La intertextualidad es una caracteristica inherente al texto cinematográfico y al televisivo, donde encontramos alusiones, citas y referencias que llegan a nosotros a través de diferentes canales y códigos. Su aparición no es casual, sino totalmente motivada. En los dibujos animados, por ejemplo, puede resultar un buen reclamo para llamar la atención del espectador adulto. En este artículo nos acercaremos al caso de la película Zootrópolis (Zootopia, 2016) para observar el uso de la intertextualidad presente en este producto de Disney. Así, podremos estudiar los diferentes tipos de intertextos y determinar a quiénes van dirigidos esos guiños y referencias.

PALABRAS CLAVE: intertextualidad, traducción audiovisual, dibujos animados.

\title{
La intertextualidad en Zootrópolis. ¿Cosa
de niños?
}

Carla Botella Tejera

Universidad de Alicante

Yeray Garcia Celades

Universidad de Alicante
Intertextuality in Zootopia. Child's Play?

Intertextuality is inherent in film and television texts, where we often find allusions, quotes or references that reach us through different channels and codes. Its presence is not a coincidence and it is fully motivated. For example, when it comes to cartoons, it might attract the attention of older viewers. In this article we will approach the film Zootopia (2016) to examine the use of intertextuality in this Disney product. This way, we will be able to analyse its different types of intertexts and establish who these hidden messages and references are addressed to.

KEY WORDS: intertextuality, audiovisual translation, animated films. 


\section{INTRODUCCIÓN}

Cuando cualquier aficionado al séptimo arte en todas sus variantes se enfrenta a la arraigada creencia popular de que «las películas de dibujos animados son solo para niños», no puede evitar mostrar cierto escepticismo. Si bien resulta obvio que el público infantil es el principal destinatario de esta clase de productos, su presencia cada vez más significativa en las listas anuales de films más taquilleros indica que acudir a las salas acompañando a los menores a su cargo tampoco debe suponer un grave problema para los mayores de la casa. Las productoras cinematográficas son más conscientes que nunca de esta situación y en los últimos años se puede apreciar cierta tendencia a incluir pequeños detalles dirigidos exclusivamente a los adultos en los estrenos del género con el objetivo de que no les resulte molesto abonar la cantidad de la entrada (o que incluso lleguen a plantearse acercarse al cine a ver una cinta animada sin la compañía de ningún niño). Este fenómeno se ha visto acentuado desde la irrupción en el panorama audiovisual de la animación generada por ordenador y, en particular, de los estudios Pixar con Toy Story (John Lasseter, 1995). Los cinéfilos y la crítica más sesuda reciben con alabanzas cada uno de los estrenos de esta productora, que suelen reportarle cuantiosos beneficios económicos. Su producción Del revés (Pete Docter y Ronnie Del Carmen, 2015) llegó a ser galardonada con el premio Óscar al mejor guion original compitiendo en igualdad de condiciones con títulos de imagen real. Otras compañías se han atrevido incluso a desarrollar largometrajes animados dirigidos en exclusiva a un público adulto y nada recomendados para menores de edad debido a la abundancia de escenas obscenas, sexuales y/o violentas en su metraje como Team America: $L a$ policía del mundo (Trey Parker y Matt Stone,
2004), Anomalisa (Charlie Kaufman y Duke Johnson, 2015) o La fiesta de las salchichas (Conrad Vernon y Greg Tiernan, 2or6), y han obtenido también resultados positivos. Creemos que podemos afirmar sin miedo a equivocarnos que hace tiempo que los dibujos animados dejaron de ser «solo para niños».

Cuando hablamos de películas de animación, nos encontramos, por tanto, ante textos ambivalentes, de acuerdo con la concepción del adjetivo aplicada a la literatura por Lotman (I977: 20I), puesto que se dirigen a dos tipos diferenciados de receptores a pesar de aparentar haber sido originadas con un solo destinatario en mente. Según Shavit (1980: 76), se puede apreciar que los textos de este tipo están formados por dos modelos textuales a la vez. Encontramos uno principal, que resulta más convencional y está destinado a la infancia, y otro secundario, algo más sofisticado, que solo será detectado por los adultos. Conservar esta dualidad tan característica será una de las principales preocupaciones del traductor de este tipo de encargos y, sin duda, influirá de manera profunda sobre su toma de decisiones, por lo que resulta interesante conocer los mecanismos que se suelen aplicar en el texto original para conseguirla.

Una de las estrategias más recurrentes para captar la atención de los mayores de dieciocho años en este género es la utilización de la intertextualidad, propiedad que puede definirse como «la aparición, en un texto, de referencias a otros textos (orales o escritos, anteriores o contemporáneos)» (Agost, I999: I03). Por supuesto, la captación de estas referencias, siempre incluidas en la narración con un propósito, dependerá del receptor y su bagaje cultural. Por este motivo, podemos deducir que un espectador adulto tendrá más posibilidades de reconocer elementos procedentes de otros productos audiovisuales que uno de corta edad y que es 
más que presumible que se hayan introducido en el guion pensando en él.

A lo largo de este artículo, nos centraremos en el caso del largometraje Zootrópolis (Byron Howard, Rich Moore y Jared Bush, 2016) como ejemplo representativo de dicho fenómeno. Su trama nos traslada hasta un universo poblado por animales antropomórficos que conviven en la moderna urbe que da título a la cinta. Allí, una conejita policía y un zorro estafador se ven envueltos en una complicada trama criminal en la que se encuentran enredados los estratos más elevados de la sociedad de la metrópoli. Este punto de partida se presta al homenaje y/o parodia de ciertos tópicos del género policiaco que nos retrotraen con facilidad a otras películas o series de televisión y, además, sirve para realizar una aguda reflexión crítica sobre el mundo real, en el que vivimos unos seres a priori no tan animales. Consigue conjugar todos estos elementos sin perder la atención de los más pequeños en ningún momento y permitiéndose introducir divertidos guiños a otros productos de la factoría Disney. Quizá ahí radique la clave de su gigantesco éxito tanto de crítica como de público.

Nuestro objetivo principal será analizar las diferentes clases de referencias que presenta, ejemplificar la complicación que pueden representar para la labor del traductor y delimitar el destinatario al que se dirigen. Quién sabe, puede que hasta acabemos dándonos cuenta de que el cine de animación nunca ha cumplido su propósito de ser considerado «para todos los públicos» de una manera tan literal como en la actualidad.

\section{EL INTERTEXTO AUDIOVISUAL FRENTE}

\section{AL LITERARIO}

Como ya hemos comentado, la intertextualidad está presente en multitud de textos, si no en todos ellos. De hecho, hemos visto que no resulta descabellado afirmar que estos beben de otros anteriores, contemporáneos y en ocasiones, como veremos, hasta futuros. Además, este fenómeno se produce en gran medida en los de naturaleza audiovisual, hacia y desde los que son posibles multitud de transvases culturales.

Sin embargo, durante mucho tiempo, la investigación se centró en la noción clásica de intertextualidad, es decir, la que se observa en los textos escritos. En ese sentido, le debemos mucho a autores como Julia Kristeva que, inspirada por otros como Bahktin, insistió en que la intertextualidad se da en el propio sistema textual y que cada texto no es sino un mosaico formado a partir de citas de otros. Es decir, una absorción y transformación de textos previos (I969: 15). A partir de sus teorías, autores como Barthes fueron más allá, afirmando que ningún escritor puede ser original, ya que solo se puede imitar aquello que otros dijeron previamente. El autor veía los textos como una especie de «tejidos» plagados de citas que provienen de diferentes fuentes culturales (I977: I46-I47). Así, para Barthes, el texto no es sino una pluralidad de voces, palabras y textos y, por lo tanto, no hay que buscar las fuentes o influencias, ya que las citas y referencias utilizadas son anónimas e intrazables (Botella Tejera, 2010: 65).

Más adelante, autores como Genette (I989) hablaban de «literatura en segundo grado», es decir, se basaban en la imagen de un pergamino en el que se transparentan los trazos de textos anteriores (Lara, 2000: 49). Para Genette existen cinco tipos de relaciones transtextuales (I989: I-Io). Entre ellas, se encuentra la intertextualidad, definida como la presencia mutua de dos o más textos, es decir, la presencia de un texto en otro. El autor lo considera un modo más explícito y literal que otras manifestaciones transtextuales, ya que se incluyen las citas (con 
y sin comillas), el plagio y la alusión (Botella Tejera, 2010: 66-67).

Nos resulta especialmente interesante el 172 acercamiento a la intertextualidad llevado a cabo por Hatim y Mason, quienes explicaban que, en el ámbito literario, la tipología de categorías intertextuales se da a partir de la relación de un texto con aquellos que lo preceden, lo inspiran o lo hacen posible (I995: I72). Los mismos autores proponen diferentes categorías a partir de la relación que se da entre en los textos. Entre ellas se encuentran la referencia, el cliché, la alusión literaria, la cita propia, el convencionalismo, el proverbio y la mediación (I990: 132).

En el terreno audiovisual, las cosas cambian. Para empezar, por la propia naturaleza de los textos audiovisuales, dada la confluencia de códigos y canales, y el hecho de que se transmitan de forma simultánea por el canal visual y el auditivo. La imagen, que además aparece en movimiento, supone un elemento diferenciador frente a los estáticos textos literarios. En ocasiones, de hecho, la imagen será fuente de intertextualidad por sí misma y, en otros casos, podrá facilitar su recepción. Rosa Agost, cuya definición ya manejábamos en la introducción de este artículo, es una de las primeras en trabajar con la intertextualidad en textos audiovisuales. En este sentido, también son interesantes las aportaciones de Martínez Sierra (2004: I72), quien ponía de manifiesto que, además de los elementos lingüísticos (orales y escritos), en los textos audiovisuales también los paralingüísticos, los visuales e incluso los sonoros pueden resultar fuente de intertextualidad.

Más recientemente, en su tesis de 2015 sobre el estudio de la recepción del cine para niños, De los Reyes (2015: 158) usaba la clasificación antes mencionada de Hatim y Mason para, centrándose en el campo audiovisual, estudiar los referentes intertextuales a través de las referen-

cias y alusiones a obras (literarias, cinematográficas, musicales...) y a través de los proverbios.

Lo que está muy claro, tanto en los textos escritos como en los de carácter audiovisual, es que el hecho de recurrir a la intertextualidad no es algo casual, sino totalmente motivado, ya sea como homenaje (a una obra, autor o personaje) o con fines puramente cómicos, a modo de parodia. Por lo tanto, a pesar de esa intencionalidad, será necesaria cierta complicidad entre el emisor y el receptor del texto para ser capaces de comprender las referencias. De hecho, Hatim y Mason (I990: 13I) hablan de "precondition for the intelligibility», que sería, además, un conocimiento compartido que debería darse en cualquier proceso comunicativo, sin el cual no se podría comprender lo que se pretendía transmitir. A este respecto, en el terreno literario, Mendoza Fillola (2001 y 2003) considera como «intertexto lector» a la capacidad y los conocimientos previos y compartidos que debe tener el lector para poder reconocer las obras a las que un texto remite. Así, la recepción del mensaje dependería de esos saberes compartidos entre el emisor y un determinado tipo de «lector previsto».

En el terreno audiovisual, son muchos los transvases culturales que pueden darse. Segovia (I998: I73), por su parte, nos propone transvases dentro del cine, dentro de la televisión o entre el cine y la televisión. Si incorporáramos otro tipo de textos, podríamos aumentar el listado con otros transvases que están a la orden del día, como el del cómic al cine y a la televisión, o incluso el que se da desde los videojuegos a las diferentes pantallas. Por supuesto, la literatura también ha sido siempre una enorme fuente de transvases culturales de todo tipo. Recomendamos la clasificación ampliada por Botella Tejera (20I2: IOI) que contempla todas las posibilidades que acabamos de mencionar. En el caso de 
este artículo, la mayoría de los intertextos estudiados vendrán de otros largometrajes, algunos de la propia factoría Disney. Sin embargo, también encontraremos ejemplos que han saltado al cine desde la televisión. Cuando estudiemos las referencias usadas en el largometraje analizado, podremos entender mejor las cuestiones relacionadas con los potenciales destinatarios y con la intención por parte de los emisores que, en este caso, serían los guionistas del film.

De todo lo anterior podemos concluir que existe un intertexto audiovisual que comparte ciertas características con el literario, pero que también tiene las suyas propias y distintivas y que llega a nosotros a través del canal auditivo y del visual. Ambos, literario y audiovisual, persiguen alguna finalidad y, por lo tanto, el conocimiento compartido entre emisor y receptor facilitará en gran medida la recepción del mensaje. A la hora de enfrentarnos a su traducción, sin embargo, deberemos ser capaces de detectarlos $\mathrm{y}$ de recurrir a las estrategias necesarias para que, en la medida de lo posible, la nueva audiencia sea capaz de percibir los mismos guiños y referencias.

\section{LA TRADUCCIÓN DEL INTERTEXTO AUDIOVISUAL}

Si ya hemos advertido de la intencionalidad clara en el uso de la intertextualidad, la labor del traductor será muy complicada, pero de tremenda importancia para conseguir que las referencias lleguen a un nuevo público y puedan causar el mismo efecto. $\mathrm{Y}$ es que, recurriendo precisamente a un intertexto cinematográfico con el que García Celades (2018: 53) cierra su Trabajo de Fin de Máster sobre la intertextualidad en el cine de superhéroes, «un gran poder conlleva una gran responsabilidad».

Para ser consecuentes con tal misión, los tra- ductores, al igual que los espectadores, deberían empezar por localizar las referencias ocultas en los textos audiovisuales. Se trataría de buscar lo que Hatim y Mason (1995: 174) denominan «señales intertextuales», que serían los elementos que llamarían nuestra atención sobre el uso de referencias. Respecto al terreno audiovisual, tendríamos que estar preparados para recibir estas señales a través de los dos canales ya mencionados y mediante el uso de diferentes códigos, como el lingüístico o el musical entre otros. Sobre las señales intertextuales audiovisuales, la última publicación de Botella Tejera (20I7: 9I) recoge la versión más actualizada de su clasificación sobre los principales mecanismos de detección del intertexto audiovisual.

En cuanto a su traducción, una vez superada la importantísima fase de documentación, habrá que tener en cuenta diferentes factores. Obviamente, como en cualquier otro proceso de traducción, la relevancia de la referencia y el grado de opacidad para la nueva audiencia entrarán en la ecuación. En el caso de las referencias televisivas, por ejemplo, podremos encontrar más dificultad de comprensión de las mismas por parte de un público distinto al del producto original, ya que muchos programas o anuncios, e incluso algunas series, no cruzan las fronteras de los países de emisión. Sin embargo, habrá que tener en cuenta que cuando las referencias que aparecen en un texto audiovisual son ya famosas, estas suelen contar también con una traducción famosa que la nueva audiencia conoce y espera escuchar (Agost, 1998: 226). Eso sí, no podremos dejar de lado otros factores profesionales o de restricciones debido a las características propias del doblaje o la subtitulación, tales como la sincronía, en el caso del primero, o la condensación en la segunda.

Hablando de transvases culturales en el cine, tema en el que nos centramos en este estudio,

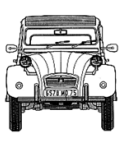

173 
Zavala (2009: 49-53) señala cuatro tipos de traducción: la intralingüística, la interlingüística, la intrasemiótica y la intersemiótica. Nosotros nos quedaremos con la que denomina traducción intrasemiótica, es decir, aquella que adopta las estrategias de la intertextualidad, como es el caso de la citación textual, la alusión, la parodia, etc. Eso sí, no podemos olvidar que, a diferencia de la literatura, los traductores de textos audiovisuales no podrán hacer uso de notas a pie de página o de glosas intratextuales que expliquen o maticen el uso de la intertextualidad. Volvemos entonces, una vez más, a recalcar la enorme responsabilidad que el traductor tiene en sus manos.

\section{LA INTERTEXTUALIDAD EN LOS DIBUJOS ANIMADOS}

Tradicionalmente, y aunque ahora tratemos de desmentirlo, hemos comentado que los dibujos animados y los niños siempre han ido de la mano a pesar de que, en muchas ocasiones, las producciones de animación buscan intencionadamente la complicidad del público adulto. Y es que, por la corta edad de los niños y por la poca experiencia compartida, es difícil que los más pequeños sean capaces de entender todas las referencias que contiene una obra. Sobre esto, Zabalbeascoa opina que, en el caso de los niños «[... no se ha tenido suficiente tiempo para adquirir un bagaje textual que permita interpretar correctamente elementos intertextuales como la alusión, la parodia, la manipulación del discurso, la ironía, el simbolismo, citas directas de otros textos, símiles y metáforas, etc.» (2000: I9). Para poder entender un texto determinado es necesario conocer una serie de textos afines al mismo, con los cuales mantiene cierta relación. Es por eso que Simone (2000: I09-IIo) nos explica que «cuando un niño oye leer un cuento tiene una cantidad de conocimientos intertextuales que le ayudan a interpretar su sistema de expectativas». El autor explica que la cantidad de experiencia precedente, textual e intertextual es lo que se convierte en calidad de interpretación. Sin esa capacidad ni esos conocimientos previos compartidos a los que aludía Mendoza Fillola (200I y 2003), podemos concluir que los niños no serán siempre el potencial receptor de la intertextualidad escondida en un texto audiovisual.

En ese sentido, sería interesante también distinguir entre diferentes tipos de intertextualidad en estas producciones. El mismo Zabalbeascoa (2000: 22-23) nos dice que, en el caso de los dibujos animados podemos, de hecho, encontrar tres diferentes: I) el más propio del género infantil, 2) el propio del género cinematográfico y 3) aquellas referencias intertextuales que suponen guiños a los adultos. Lo curioso de la película en la que se basa nuestro estudio es que sería posible encontrar referencias de los tres tipos.

Por otra parte, se debería también establecer una distinción entre las diferentes producciones animadas, ya que hay diferencias muy claras que pueden suponer un mayor o menor uso de referencias intertextuales. Hernández (2005: 2I2-2I3), por su parte, distingue entre el público de estas producciones, ya que opina que la adecuación al mismo es la que supondrá un mayor o menor éxito de taquilla. La autora comenta que dentro del público infantil existen diferentes intervalos de edad en grandes salas: de 7-I2 y de I2 en adelante, siendo muy escaso el número de producciones dirigidas a los de 0-7. Por su parte, Agost (1999: 85) ofrece una serie de ejemplos teniendo en cuenta a quién va dirigida la producción y si se trata de cine o de televisión. Para Agost habría películas para niños, como El rey León (Rob Minkoff y Roger Allers, I994); pelí- 
culas para jóvenes y adultos, como ¿̇Quién engañó a Roger Rabbit? (Robert Zemeckis, 1988); series para niños, como Bola de dragón (I986), y series para jóvenes y más mayores, como es el caso de la protagonizada por la longeva familia Simpson. Es importante mencionar que, sobre todo a partir de Los Simpson (1989), las series de animación para adultos han inundado nuestras pantallas y nuestras casas de intertextos imposibles de percibir por los más pequeños. Tanto la serie de los personajes amarillos como otras tales como South Park (1997), Futurama (1999), Padre de familia (1998), Padre made in USA (2005) o las más recientes Hora de aventuras (2010), Rick y Morty (2013) o BoJack Horseman (20I4) son fuentes constantes de referencias y alusiones de todo tipo.

Sin embargo, en cuanto al caso que nos ocupa, es decir, el cine de animación, podemos observar que la recepción de este tipo de producciones ha sido objeto de estudio de muchos trabajos recientes. Ya hemos mencionado a Zabalbeascoa (2000) que, entre otras investigaciones sobre dibujos animados, se acercaba al doblaje de varias películas de Walt Disney. Por su parte, también cabe mencionar las diferentes aproximaciones de Lorenzo y Pereira (I999, 2000 y 2014) que, entre otros, se asomaban al largometraje Blancanieves y los siete enanitos (David Hand, Larry Morey, Wilfred Jackson, William Cottrell, Ben Sharpsteen, Percival C. Pearce, 1937). Lorenzo, esta vez en solitario (2008), investigaba sobre el doblaje a español peninsular de la película Pocahontas (Mike Gabriel y Eric Goldberg, 1995) y, más adelante, en compañía de Rodríguez (2015) lo hacía sobre la intertextualidad en la película Donkey Xote. Otro autor a quien ya hemos mencionado previamente, De los Reyes, dedicaba su tesis (2015) al estudio de la recepción del cine infantil y, más recientemente (20I7) publicaba un artículo sobre el estudio de la música referencial y su influencia en el cine de animación. Centrada en el tema concreto de las referencias, López González (2015) escribía también su tesis sobre la traducción de la alusión como fuente de creación humorística. Como corpus de trabajo, la autora se basaba en los largometrajes de animación producidos por DreamWorks entre 2001 y 2012.

Acercándonos ya a estos largometrajes, podemos afirmar que la concepción actual del cine de animación como un género no destinado exclusivamente a la infancia y repleto de referencias a la cultura popular y elementos humorísticos de carácter más adulto se debe en gran medida a la existencia de Shrek (Andrew Adamson y Vicky Jenson, 200I). Esta parodia en tono gamberro de los cuentos de hadas en la que el ogro se convertía en el «príncipe azul» del relato, obra de la por entonces semidesconocida división de animación del estudio DreamWorks, supuso toda una revolución para el público y no tardó en integrarse en el imaginario popular, originando una longeva saga y cientos de productos asociados. Los intertextos campaban a sus anchas en una cinta cuya premisa consistía en subvertir los roles de los personajes de los cuentos populares, acompañados de éxitos musicales que nunca dejarán de sonar por la radio y secuencias calcadas de películas de moda como Matrix (Hermanas Wachowski, 1999). Esta fórmula (elevada a la enésima potencia) acabaría convirtiéndose en la firma de DreamWorks Animation, como demuestran franquicias como Madagascar o Kung Fu Panda. Puede que en alguna ocasión hayan descuidado los guiones de sus propuestas, pero nunca la presencia de la intertextualidad.

Por otra parte, Pixar, su contrincante más directo, se ha especializado en añadir un componente más profundo y dramático a sus historias que se aleja de la infantilización que uno 
podría esperar de los dibujos animados, y consigue así ganarse el cariño de la crítica además del agrado del público. A pesar de estar especializados en una disciplina considerada menor en ciertos círculos, estos estudios cuentan con 28 premios Óscar en su haber tras veintidós años de existencia. Aunque recurren a ella de forma más dosificada, para ellos la intertextualidad también es una herramienta narrativa muy útil. Tres de sus films más populares beben de los clichés de géneros cinematográficos inesperados para ofrecer algo nuevo: Los Increíbles (Brad Bird, 2006) no dejaba de ser una película de superhéroes, $W A L L \bullet E$ (Andrew Stanton, 2008), un relato de ciencia ficción y Monstruos University (Dan Scanlon, 20I3), una comedia universitaria. La influencia de los creadores de Toy Story en el resurgimiento actual del departamento de animación de Disney y en largometrajes como Zootrópolis es clara.

Dado el incremento en la oferta de plataformas de entretenimiento que ha tenido lugar durante los últimos años, los guiños de los dibujos animados llevan un tiempo sin estar centrados únicamente en el séptimo arte. Otro producto de Disney, „Rompe Ralph! (Rich Moore, 20I2), ya presentaba un sinnúmero de cameos de personajes procedentes de videojuegos como el erizo Sonic, Pac-Man (conocido como Comecocos en nuestro país) o la luchadora Chun-Li de Street Fighter varios años antes de la existencia de Ready Player One (Steven Spielberg, 2018). De hecho, llevando esta táctica al extremo, se ha llegado a estrenar en salas un largometraje animado basado en una aplicación para móviles: Angry Birds, la película (Clay Kaytis y Fergal Reilly, 2or6).

Aunque la industria española lleva años demostrando que podemos producir cine con la misma calidad que en Hollywood a pesar de contar con unos medios más modestos, parece que el cine de animación se le resistía. Ninguno de los estrenos conseguía atraer público a las salas ni causar algún tipo de impacto cultural. Al menos, hasta que entró en juego la intertextualidad. Tadeo Jones, un personaje que referencia sin demasiada sutileza a cierto arqueólogo encarnado por Harrison Ford, ha sido el primer dibujo animado con denominación de origen española que ha conseguido convertirse en una marca comercial potente. Ya son dos las historias que ha protagonizado en la gran pantalla: Las aventuras de Tadeo Jones (Enrique Gato, 20I2) y Tadeo Jones 2. El secreto del Rey Midas (Enrique Gato, 20I7). La primera entrega fue la película de animación española más taquillera de la historia y la segunda también contó con una generosa recaudación, así que parece que ha llegado para quedarse. Sin que apenas nos hayamos dado cuenta, la intertextualidad se ha convertido en un ingrediente indispensable de las producciones de dibujos animados.

\section{LA INTERTEXTUALIDAD EN ZOOTRÓPOLIS}

Como ya hemos avanzado, nos centraremos en el film Zootrópolis como ejemplo representativo de esta tendencia a recurrir a la intertextualidad con el objetivo de captar la atención de los espectadores adultos tan presente en el cine de animación durante los últimos tiempos.

Es muy probable que su estreno en marzo de 2016 no fuera de los más esperados entre los aficionados a la factoría del ratón Mickey, pero, pasados unos años, su impacto cultural y su éxito entre crítica y público queda fuera de toda duda. Según la página web Box Office Mojo, a lo largo de todo su recorrido comercial en salas de cine consiguió amasar la impresionante cantidad de I.023 millones de dólares en taquilla a nivel mundial. Asimismo, pocos largometrajes animados pueden alardear de contar con un $92 \%$ 
de impresiones positivas por parte de sus espectadores y un $98 \%$ de críticas a favor firmadas por periodistas especializados en medios de carácter cinematográfico de acuerdo con los datos de la página Rotten Tomatoes. Ni que decir tiene que obtuvo el premio Óscar a la mejor película de animación de ese año. La hipótesis de que la cinta lograra coleccionar todas estas cifras y reconocimientos contando únicamente con el beneplácito del público infantil no parece sostenerse con facilidad, así que podemos suponer que su metraje contiene una serie de elementos que también resultan atractivos en mayor o menor medida para los espectadores adultos.

$\mathrm{Su}$ guion, registrado como obra de Jared Bush y Phil Johnston aunque la historia pasara por diversas manos, narra una aventura de Judy Hopps, la primera coneja en conseguir un puesto como agente de policía en el cuerpo policial de la ciudad de Zootrópolis. Con el propósito de conseguir ser valorada en un mundo dominado por especímenes mucho más brutos que ella, acabará formando equipo con un zorro aficionado a la estafa, Nick Wilde, para resolver un caso de asesinato aparentemente sencillo tras el que se esconde una compleja trama política que pone en jaque el futuro de la metrópolis. La contraposición de los dos personajes principales permite a los guionistas incorporar cierto subtexto sociopolítico que pasará desapercibido para los más pequeños de la casa, pero que sus progenitores encontrarán interesante. La visión negativa de los animales depredadores por parte de sus conciudadanos (y posibles presas) sirve como metáfora de una de las plagas que, por desgracia, asola nuestro mundo: el racismo. Nunca está de más que nos recuerden que las apariencias engañan, tengamos la edad que tengamos. Además, volviendo a la propiedad textual que nos ocupa, el punto de partida de la cinta se presta a replicar todos los lugares comunes de las películas de género policiaco. No falta ninguno: el arduo entrenamiento en la academia, la ceremonia de graduación a la que acude un político que acabará siendo esencial para la trama, la agente recién llegada a la que sus compañeros dejan de lado en su nueva comisaría... Aunque no se traten de unas referencias tan específicas como otras que pasaremos a comentar a continuación, ya podemos apreciar la intención de mantener la atención del espectador mayor de edad a través de este tipo de alusiones y hacernos una idea de la relevancia de la intertextualidad en el largometraje.

Dada su influencia en la cultura popular, una de las señas de identidad de los productos de Disney de unos años a esta parte han sido los guiños a otras obras de la compañía. En este caso hablamos de intertextos que aportan una nueva capa al visionado en familia, puesto que pueden ser percibidos por cualquiera de los miembros, sin importar su edad.

Como hemos señalado con anterioridad, la intertextualidad puede manifestarse a través de diferentes canales en el medio cinematográfico. En animación resulta mucho más sencillo contar con cameos de personajes populares o incluir elementos reconocibles como atrezo (incluso a través de la voz de los actores de doblaje) porque no existen los problemas habituales de presupuesto o logística, solo los de derechos de autor, así que el canal visual suele ser el preferido por Disney para citarse a sí misma. En este largometraje, si forzamos la vista, podemos encontrar camuflados con el entorno a un muñeco de Mickey Mouse, al camaleón de Enredados (Nathan Greno y Byron Howard, 20ro), al muñeco de nieve Olaf de Frozen: El reino de hielo (Chris Buck y Jennifer Lee, 20I3) y al robot Baymax de Big Hero 6 (Chris Williams y Don Hall, 20I4). 
De hecho, los responsables de Zootrópolis se atreven incluso a hacer referencia a futuros estrenos de la productora que ni siquiera habían llegado a las pantallas y todavía estaban en desarrollo. En una de las secuencias más divertidas de la película, nuestros protagonistas se encuentran con un mantero que vende películas de forma ilegal en la calle. Un plano detalle nos permite echar un vistazo a las carátulas que expone en su puesto. Todas ellas contienen juegos de palabras que fusionan títulos muy reconocibles de la casa del ratón con el reino animal. Como decíamos, no solo vemos los carteles imaginarios de Wrangled (contrapartida de Enredados), Wreck-It Rbino (¡Rompe Ralph!) y Pig Hero 6 (Big Hero 6), sino que también se alude a largometrajes que por aquel entonces no se habían estrenado como es el caso de Merwana, en referencia al título original de Vaiana (John Musker, Ron Clements, Don Hall y Chris Williams, 20r6), que fue Moana. Encontramos incluso parodias de títulos que todavía se encontraban en preproducción como Giraffic (Gigantic) o Floatzen 2 (Frozen 2). Tanto se adelantaron en el tiempo que la producción de Gigantic acabaría siendo cancelada. El aficionado a Disney que no tenga ninguna noción de la lengua de Shakespeare lo tiene un poco difícil para captar estos curiosos homenajes, puesto que en la versión que se estrenó en nuestro país no se ofrece ningún equivalente mediante subtítulos o doblaje. Sorprende que, habiendo alterado todos los textos que aparecen en pantalla a lo largo del metraje para traducirlos y que pudieran ser comprendidos por el espectador español, nadie se decidiera a aplicar esa fórmula también en esta escena. Algo similar ocurre en el momento en que descubrimos que el iPod de Judy está repleto de canciones procedentes de films clásicos de la factoría, pero en esa ocasión la ausencia de traducción resulta más compren- sible dada la breve permanencia de las referencias en pantalla.

E1 canal auditivo también es un recurso extremadamente útil para la intertextualidad. Los diálogos permiten incluir citas literales de una forma más directa y más similar a la literatura, como ya hemos podido observar. En Zootrópolis encontramos un ejemplo muy claro de esta tendencia. En un momento en el que el comisario abronca a la agente Hopps, acaba exclamando: "Life isn't some cartoon musical where you sing a little song and your insipid dreams magically come true. So, let it gon. No solo se realiza una referencia directa al tema principal de la banda sonora de Frozen: El reino de bielo, sino que también se incluye un comentario de carácter metatextual sobre el esquema narrativo habitual de las cintas animadas clásicas de Disney. Una vez más, se trata de un intertexto que puede ser detectado por todos los rangos de edad, pero que tendrá connotaciones diferentes para cada uno de ellos. El equivalente que nos ofrece el doblaje español es el siguiente: «La vida no es una película de animación en la que cantas una canción y tus insípidos sueños se hacen realidad por arte de magia. A mí no me cantes "Suéltalo"». Pese a que en esta versión el guiño se hace más explícito y puede resultar un poco forzado, se antoja la única manera de mantener el equivalente acuñado del referente y hacerlo reconocible.

Por supuesto, las alusiones no se limitan únicamente al universo Disney. Hay dos secuencias que hacen referencia directa y nada disimulada a dos productos audiovisuales externos a la compañía que, esta vez sí, solo conocerán los más mayores. Por un lado, uno de los personajes secundarios más memorables es el líder de una familia mafiosa, que recuerda de forma inevitable al Vito Corleone de El padrino (Francis Ford Coppola, I972). Conocido únicamente 
como Mr. Big en la versión original, el doblaje va un paso más allá y, por si había algún atisbo de duda, lo renombra como Don Bruto Mascarpone. Su aparición replica la popular escena que abre la adaptación al cine de la obra de Mario Puzo, incluyendo de manera textual la icónica frase «Vienes a mi casa el día de la boda de mi hija». Por otra parte, cerca del desenlace de la historia, Judy y Nick se adentran en un vagón de tren abandonado donde alguien ha organizado un laboratorio clandestino. A cualquier seguidor de Breaking Bad (2008) le resultará familiar la indumentaria del criminal que se encuentra en su interior y la sustancia azul que está sintetizando, puesto que se tratan de dos de los elementos más icónicos de esta serie de televisión. Poco después, dos ovejas llamadas Walter (Woolter en el original, haciendo un juego de palabras con la denominación anglosajona para «lana») y Jesse, al igual que los protagonistas de la serie, tocan a la puerta del vagón. Teniendo en cuenta los temas que tratan las obras referenciadas, dudamos que estos dos momentos produzcan un gran impacto en el público infantil. Sin embargo, puede que sí esbocen una sonrisa en el rostro de otro tipo de espectadores, que quizá pensaban que esta película no estaba dirigida a ellos.

En resumen, la importancia de la conservación de la intertextualidad para conseguir replicar el guion de este largometraje en otro idioma queda fuera de toda duda. Preguntada sobre el tema en una entrevista con García Celades (2018) para el blog Luces, cámara, ¡traducción!, la encargada de la traducción para doblaje en España de esta cinta, Lucía Rodríguez, se declaraba no "partidaria de "simplificar" o "infantilizar" una traducción, aunque a priori esté dirigida a niños. Si el diálogo original contiene vocabulario que pueda considerarse "difícil", por ejemplo, creo que mi función como traductora es plasmarlo de la misma manera». A continuación añadía que su máxima es respetar el trabajo realizado por los creadores y explicaba que «si el original tiene subtexto adulto o referencias que no son infantiles, basta con que tratemos de no pasarles por encima y plasmarlas de forma simétrica en la traducción. Basta con no añadir ni restar cosas». Quizá esa sea la clave para enfrentarse a la traducción de la intertextualidad y vencer: no añadir ni restar, sino utilizar todos los medios disponibles para tratar de salvaguardar cada referencia y conseguir que el nuevo receptor sea capaz de detectar todas ellas.

\section{CONCLUSIONES}

Como hemos comprobado, la intertextualidad se ha convertido en un ingrediente imprescindible para la receta que conforma una película de animación exitosa. Recurrir de forma voluntaria a referencias a otras obras artísticas siempre suele originar una respuesta positiva, puesto que establece una fuerte relación de complicidad entre los creadores y el público, participantes en un acto comunicativo de carácter íntimo que resultará incomprensible para otros interlocutores. Como postula Antonopoulou (2004: 245), reconocer una alusión puede llegar a producir cierta sensación de placer y satisfacción en el receptor debido al relativo esfuerzo que conlleva. Dado su papel clave a la hora de sustentar cualquier parodia o sátira, nos encontramos ante un recurso especialmente útil para la comedia, una de las principales armas de los dibujos animados en su pugna por atraer la atención de los adultos durante los últimos años.

Por todas estas circunstancias, los intertextos supondrán un gran reto durante el proceso de traducción. Fuentes (200r: 70) apunta que requieren del uso de diferentes estrategias por parte del traductor y que el efecto de los equiva- 
lentes sobre los espectadores varía según el contexto cultural. Esto se acentúa, sobre todo, cuando forman parte integral de cintas de carácter humorístico. Todo un experto en comedia como Nash (I987: 9) explica que en la elaboración de los chistes de este tipo inciden varios elementos que necesitan ser comprendidos junto a su carga cultural y social. Nuestro sentido del humor es el mismo que el de aquellas personas con una visión del mundo similar gracias al conocimiento compartido. Un conocimiento que es probable que, en algunas ocasiones, muchos niños pequeños no compartan con sus progenitores. De ahí la importancia de la capacidad de documentación de los profesionales encargados de la traducción de esta oleada de films animados repletos de intertextos que ha llegado a la cartelera. Deberán ser capaces de detectar cada uno de ellos, deducir a qué clase de receptor van dirigidos (teniendo en cuenta, de acuerdo con lo expuesto, factores como su edad) y otorgarles un equivalente que facilite su percepción en otro idioma y cultura.

El largometraje en el que nos hemos centrado, Zootrópolis, supone un ejemplo perfecto de este fenómeno. A lo largo de sus ciento ocho minutos de metraje podemos vislumbrar decenas de referencias a obras previas, propiedad tanto de Disney como de otras productoras, que se nos presentan por medio del canal visual y el auditivo. Muchas de ellas pueden ser reconocidas por menores y mayores de edad, puesto que aluden a personajes, frases memorables o canciones procedentes de largometrajes de dibujos animados. Algunas de las películas citadas ni siquiera se habían estrenado, en una curiosa estrategia que mezcla la publicidad con el metalenguaje. Por otra parte, el resto de los guiños resultan opacos para los más pequeños de la casa de forma inevitable (y voluntaria). Destacan dos secuencias cuya única razón de ser consiste en referenciar a un par de productos audiovisuales destinados a un público muy adulto, El padrino y Breaking Bad, mediante la inclusión de sus elementos más icónicos. En la traducción para doblaje al castellano se ha cuidado la transferencia a nuestro idioma de todos los intertextos y se ha optado por recurrir a sus equivalentes acuñados, llegando incluso a añadir aspectos que no existían en el original, como el apellido de Don Bruto Mascarpone, para facilitar su detección. Solo se ha ignorado su adaptación en algunos casos transmitidos por medio del canal visual.

Tras este análisis, podemos concluir que los responsables de las películas de dibujos animados que llegan a nuestras salas en la actualidad son más que conscientes de la necesidad de atraer a personas de todas las edades si quieren que sus productos sean exitosos. El principal método al que recurren para conseguir este objetivo, aparte de tratar temas más complejos y presentar un sentido del humor más sofisticado, es la inclusión de intertextualidad. Será tarea del traductor cuidar al máximo que este aspecto tan relevante se transmita a la lengua meta sin sufrir ningún tipo de pérdida durante el proceso y respetando la intención original del autor. Tendrá que preocuparse por no ignorar ninguna referencia, documentarse sobre los equivalentes acuñados de cada uno de los intertextos y hallar la solución más apropiada para mantenerlos en su traducción. Resultará determinante que tenga muy presentes a todos los posibles receptores a los que pueden ir dirigidos una clase de largometrajes que muchos denominan como «infantiles» de forma despectiva. Al fin y al cabo, las películas de género «familiar» nunca han sido tan fieles a su nombre como ahora.

RECIBIDO EN MAYO DE $20 I 8$ ACEPTADO EN NOVIEMBRE DE 2018 VERSIÓN FINAL DE JUNIO DE 2019 


\section{REFERENCIAS BIBLIOGRÁFICAS}

Agost, Rosa (I998): «Traducció i intertextualitat: el cas del doblatge» en Meseguer, Luis y Maria Luisa Villanueva (eds.) Intertextualitat $i$ recepció, Castelló: Servei de comunicació i publicacions de la Universitat Jaume I, 219-244

Agost, Rosa (I999): Traducción y doblaje: palabras, voces e imágenes, Barcelona: Ariel.

Antonopoulou, Eleni (2004): «Humor Theory and Translation Research: Proper Names in Humorous Discourse», Humor, the International Journal of Humor Research, 17:3, 219-255.

Barthes, Roland (I997): The Death of the Author, London: Fontana Press.

Botella Tejera, Carla (20Io): El intertexto cinematográfico y su traducción. Referencias cinematográficas paródicas en Family Guy. Tesis presentada en el Departamento de Traducción e Interpretación de la Universidad de Alicante.

Botella Tejera, Carla (20I2): «La intertextualidad paródica como transvase cultural. El papel del traductor» en Mogorrón huertas, Pedro y Salah mejri (eds.) Langues spécialisées, fixement et traduction, Alicante: Publicaciones de la Universidad de Alicante, 97-IIo.

Botella Tejera, Carla (20I7): «La traducción del humor intertextual audiovisual. Que la fuerza os acompañe», MonTI, 9, 77-ıoo.

De los Reyes lozano, Julio (2015): La traduction $d u$ cinéma por les enfants. Une étude sur la réception. Tesis presentada en la Universitat Jaume I y la Université de Reims Champagne-Ardenne.

De los Reyes lozano, Julio (2OI7): «La música referencial y su influencia en el cine de animación», InTRAlinea, I9, <http://www.intralinea.org/ specials/article/musica_referencial_y_su_influencia_en_la_traduccion_del_cine_de_animacion] > [consulta: 23-V-2018].

Fuentes, Adrián (200I): «Estudio empírico sobre recepción del humor audiovisual", en Lorenzo, Lourdes y Ana María Pereira (eds.) Traducción subordinada (II). El subtitulado (inglés-españoll galego), Vigo: Servizo de Publicacións da Universidade de Vigo, 69-84.

García Celades, Yeray (2018): "Zootrópolis, una animalada de traducción. Entrevista con Lucía Rodríguez», Luces, cámara, jtraducción!, <http://
lucescamaratraduccion.blogspot.com.es/20I7/I2/ zootropolis-una-animalada-de-traduccion.html> [consulta: $\mathrm{I6}$-V-20I8].

García Celades, Yeray (2018): ¡Vengadores, reunios! La intertextualidad en el cine de superhéroes. Trabajo de Fin de Máster presentado en el Departamento de Traducción, Interpretación y Estudios de Asia Oriental de la Universitat Autònoma de Barcelona.

Genette, Gérard (1989): Palimpsestos, Madrid: Taurus.

Hatim, Basil e Ian Mason (i99o): Discourse and the Translator, Essex and New York: Longman.

Hatim, Basil e Ian Mason (i995): Teoría de la traducción: una aproximación al discurso, Barcelona: Ariel.

Hernandez Bartolomé, Ana Isabel (2005): «E1 cine de animación: un caso especial de traducción audiovisual», en Merino, Raquel et al (eds.) Transvases culturales: Literatura, Cine y Traducción 4, País Vasco: Servicio Editorial de la Universidad del País Vasco, 2II-223.

Kristeva, Julia (1969): Desire in Language: A Semiotic Approach to Literature and Art, New York: Columbia University Press.

Lara Rayo, Carmen (2007): Las voces y los ecos. Perspectivas sobre la intertextualidad, Málaga: Analecta Malacitana.

López GONZÁlez, Cristina (2015): La alusión como fuente de creación de bumor y su traducción: análisis del cine de animación de Dreamworks (200I-20I2). Tesis presentada en la Universidade de Vigo.

Lorenzo, Lourdes (2005): «Funcións básicas das referencias intertextuais e o seu tratamento na tradución audiovisual», Quaderns. Revista de Traducció, I2, I33-I5O.

Lorenzo, Lourdes (2008): «Estudio del doblaje al español peninsular de Pocahontas», en Ruzicka, Veljka (ed.) Diálogos intertextuales, Frankfurt am Main: Peter Lang, 89-1o6.

Lorenzo, Lourdes y Ana María Pereira (I999) «Blancanieves y los siete enanitos, radiografía de una traducción audiovisual: la versión cinematográfica de Disney en inglés y en español», en Caramés, José Luis, Carmen Escobedo y Jorge Luis Bueno (eds.) El Cine: otra dimensión del discurso artístico, vol. I, Oviedo: Universidad de Oviedo, 469-483.

Lorenzo, Lourdes y Ana María Pereira (2000): 


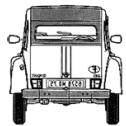

182
«Tratamiento del lenguaje del niño y de sus juegos en la traducción: The Giver y sus versiones en español y gallego», Trans. Revista de Traductologia, 4, I35-I39.

Lorenzo, Lourdes y Ana María Pereira (200i): «Doblaje y recepción de películas infantiles», en Pascua, Isabel (coord.) La traducción. Estrategias profesionales, Las Palmas de Gran Canaria: Universidad de las Palmas de Gran Canaria, I93- 203.

Lorenzo, Lourdes y Beatriz Rodríguez (2015): «La intertextualidad en los textos audiovisuales: el caso de Donkey Xote», Ocnos, I3, II7-I28.

Lotman, Juri (I977): "The Dynamic Model of Semiotics System", Semiotica, 2I, I93-210.

Martínez Sierra, Juan José (2004): Estudio descriptivo y discursivo del bumor en textos audiovisuales. El caso de los Simpson. Tesis doctoral presentada en el Departamento de Traducción y Comunicación de la Universidad Jaume I.

Mendoza fillola, Antonio (200I): El intertexto lector. El espacio de encuentro de las aportaciones del texto con las del lector, Cuenca: Ediciones de la
Universidad de Castilla la Mancha.

Mendoza Fillola, Antonio y Pedro C. Cerrillo (2003): Intertextos: Aspectos sobre la recepción del discurso artístico, Cuenca: Ediciones de la Universidad de Castilla la Mancha.

Pereira, Ana María y Lourdes Lorenzo (20I4) Diálogos intertextuales 6: The Lion King/El Rey León, Frankurt am Main, Berlin, Bern, Bruxelles, New York, Oxford, Wien: Peter Lang.

Nash, Walter (1987): The Language of Humour, London \& New York: Longman.

Shavit, Zohar (I980): «The Ambivalent Status of Texts: The Case of Children's Literature», Poetics Today, Vol. I:3, 75-86.

Simone, Raffaelle (2000): La tercera fase. Formas de saber que estamos perdiendo, Madrid: Taurus.

ZabalbeascoA, Patrick (2000): "Contenidos para adultos en el género infantil: el caso del doblaje de Walt Disney», en Ruzicka, Veljka, Celia Vázquez y Lourdes Lorenzo (eds.) Literatura infantil y juvenil: tendencias actuales en investigación, Vigo: Universidade de Vigo, I9-30. 